\title{
Oral lichenoid contact lesion to amalgam restoration: a case report
}

\author{
İsmail Uzun'”, Buğra Güler', Taha Özyürek' and Kaan Gündüz²
}

*Correspondence: ismail.uzun@omu.edu.tr

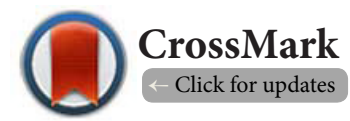

'Department of Endodontics, Faculty of Dentistry, Ondokuz Mayıs University, Samsun, Turkey.

${ }^{2}$ Department of Oral and Maxillofacial Radiology, Faculty of Dentistry, Ondokuz Mayıs University, Samsun, Turkey.

\begin{abstract}
Amalgam has been used for nearly 150 years in dentistry and it is still being used because of advantages such as low cost, ease of handling, physical characteristics like diversity in applications and low frequency of local and systemic biological side effects. On the other hand the disadvantages of dental amalgam comprise poor aesthetics, local degradation, occasional allergic responses to some of its components or degradation products, and the toxicity of mercury. Amalgam and/or its components may cause a type IV hypersensitivity reactions on the oral mucosa. Most patients with oral lichen planus (OLP) have no evidence of any association with dental restorative materials. However, contact or proximity to restorations involving amalgam or other materials causes some lichenoid reactions that is to say, lesions that clinically and histologically resemble lichen planus (LP), but have an identifiable etiology. These reactions are presumably due to allergic or toxic reactions to compounds released or generated. The present case report presents a patient with a unilateral oral lichenoid reactions (OLRs) to an amalgam restoration in the right mandibular molar region.
\end{abstract}

Keywords: Oral lichenoid reactions, oral lichen planus, amalgam restoration, oral mucosa

\section{Introduction}

Many dental materials and medicaments contain substances that can cause hypersensitivity reactions of the oral mucosa or the skin [1-3]. Generally, the allergenic substances in the dental environment are local anesthetic agents [4], antibiotics [5], restorative materials [6] and latex [7]. The symptoms are normally classified as delayed hypersensitivity reactions (type IV), and they were called oral lichenoid reactions (OLRs) by Finne et al [8]. OLRs affect oral mucosa in direct contact with amalgam restorations, and they represent a delayed, type IV, cell-mediated immune response to mercury or many metals, such as gold, palladium, nickel, chrome, and cobalt, may induce OLRs $[\mathbf{8 , 9}]$, and but the material most frequently associated with OLRs is dental amalgam, and the lesions are the consequence of a hypersensitivity to one of its components, often mercury, but sometimes copper, zinc, or tin [8-12].

The clinical occurrence of OLRs is similar to oral lichen planus. OLRs are often seen in direct topographic relation to the offending agent and are generally unilateral, and they can be reticular, in the form of plaques, atrophic and erosive or a combination of the foregoing. However, classical OLP presents as bilateral and symmetrical, white, papular/reticular or red atrophic/ulcerative lesions affecting all areas of the oral mucosa [12-14]. The possible etiologic factors of OLP include genetic background, infectious agents, autoimmune reactions, immunodeficiency, chronic liver disease, drugs, chemicals, stress, trauma, food allergies, diabetes, hypertension, malignant neoplasms, electrogalvanism and dental materials $[15,16]$. Some authors believe that a contact allergy to amalgam or other factors mentioned above causes OLP $[16,17]$, whereas others have claimed the existence of two different diseases: OLRs related to amalgam; and OLP as an idiopathic disorder [18-21].

Despite the development of various new dental restorative materials, dental amalgams remain the most commonly used posterior restorative materials in practice. However, the literature includes very few reported cases of OLRs, and almost all of the reported OLRs cases have involved hypersensitivity reactions to mercury. The present case report presents a patient with a 
unilateral OLR to a buccal amalgam restoration in the right mandibular molar region.

\section{Case report}

A 46-year-old woman was referred to our clinic with a complaint of soreness affecting the right buccal mucosa, which was worsened by consuming spicy foods and acidic drinks. She had received an amalgam restoration 2 years earlier, and she first noticed symptoms 6 months before presentation, with the symptoms becoming progressively worse with time. Her medical history was noncontributory; she was taking no medications and had no known allergies. Intraoral examination disclosed the presence of a reticular, atrophic, lightly erythematous lesion affecting the buccal mucosa of right mandibular first molar side. The lesion was in direct contact with the amalgam restoration (Figures 1 and 2). The associated right mandibular first molar responded within normal limits to electric pulp testing. The remainder of the oral mucosa was normal.

Given the close association of the lesions with the amalgam restorations, a provisional diagnosis of a lichenoid reaction to amalgam was made and the patient was patch tested using the European Standard and Dental Materials Series (Trolab Biodiagnostics Ltd, Worcestershire, UK) patch test allergens. A strongly positive response to mercury (Trolab allergen E0602, $1 \%$ ammoniated mercury in petrolatum) and a slightly weaker response to amalgam (Trolab allergen E2509, 5\% amalgam in petrolatum) were obtained after 72 hours). The patient received local anesthesia of $2 \%$ lidocaine with 1:100,000 epinephrine. The

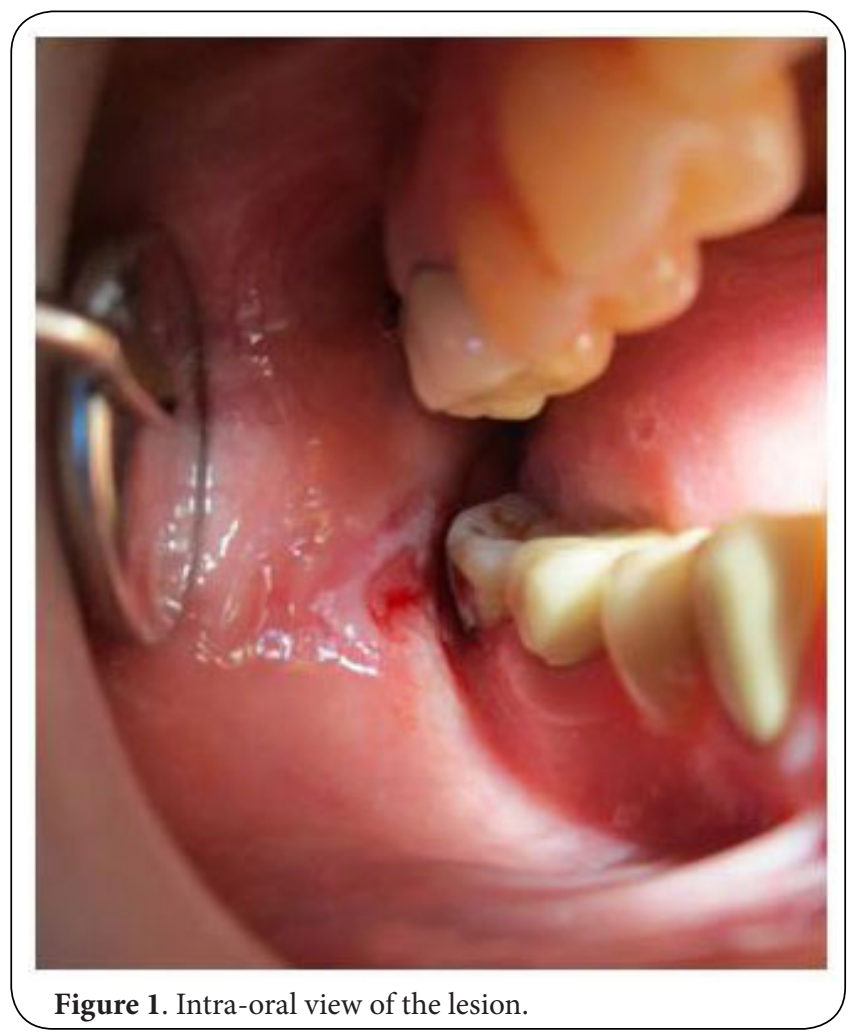

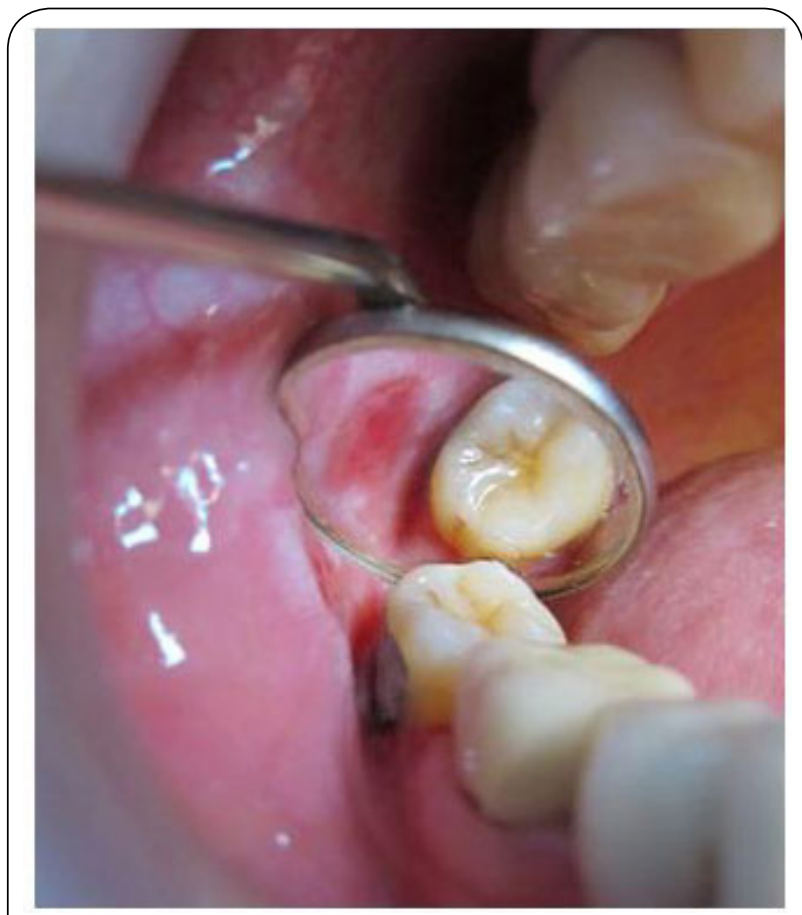

Figure 2. Buccal lichenoid reaction to an amalgam restoration.

amalgam restoration was removed under a rubber dam with copious irrigation and a high aspiration volume. The cavity was restored with light-cured posterior composite resin (Filtek p60, 3M ESPE, Seefeld, Germany). The patient was reviewed after 1 month, and the lesion was resolved (Figure 3). At the 12-month follow-up, no lesion was seen, and the patient had no discomfort (Figure 4).

\section{Discussion}

Despite the common use of amalgam as a posterior restorative material, there have been a few reported cases of hypersensitivity to amalgam, and the most common type reported is delayed oral lichenoid reaction $[\mathbf{1 0 , 2 2 ]}$. OLRs caused by amalgam restorations can be found in the literature, with symptoms such as eczema, urticaria, wheals on the face and limbs, rashes and sometimes pink or Kawasaki disease $[\mathbf{2}, \mathbf{1 2}, \mathbf{2 3}]$. In several cases, systemic reactions have been noted [24]. OLRs are not usually seen, likely because of amalgam's insolubility and the saliva's washing function $[\mathbf{2 5}, \mathbf{2 6}]$.

When haptens contact the oral mucosa, the reaction starts. A hapten is an incomplete antigen that binds to proteins/ counterparts to produce complete antigens [27]. Sensitization usually occurs through contact of hapten with the oral mucosa. Rarely, sensitization may also occur by contact of hapten with skin. Memory T cells are activated soon after the initial exposure. On re-exposure to the same allergen, a type IV hypersensitivity reaction occurs $[\mathbf{2 3}, \mathbf{2 4}]$. This reaction may be delayed by at least 48 hours and the clinical presentation may vary depending on 


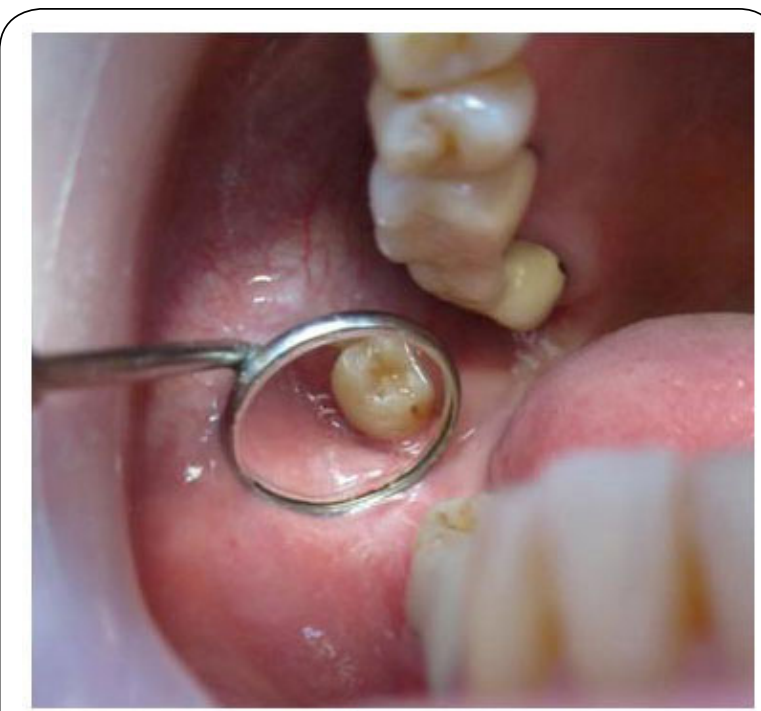

Figure 3. After removal of the offending amalgam restoration. With a filling made of composite restorations (one-month follow-up).

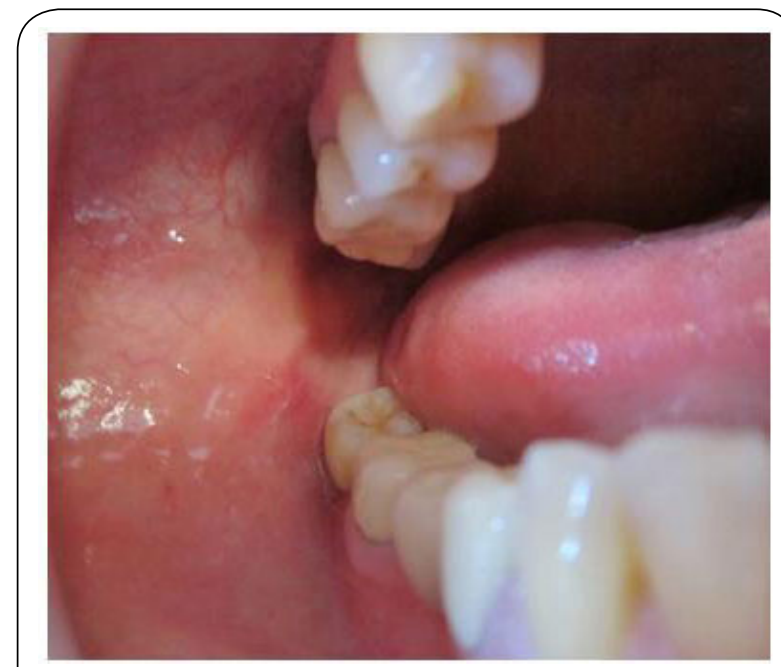

Figure 4. The lesion has completely disappeared (one year follow-up).

the severity of the reaction. These reactions can be either acute or chronic $[24,30,31]$. Clinical presentations vary based on the nature of reaction, type of allergen site and duration of contact. Patients with acute lesions may present with burning or redness $[8,16,24]$. Vesicles are rarely seen and if present rupture in a short while after formation. Chronic lesions typically present as areas of erythema, edema, desquamation and occasionally ulceration. In addition, allergic contact stomatitis can also present as erosions with rough surface and irregular borders, often surrounded by a red halo $[8,16,24,30,31]$. In this case, the corrosion products of amalgam, including mercury, tin, copper and zinc, might have acted as haptens and started the inflammatory process, leading to a delayed oral lichenoid reaction.

The lesions of OLRs are similar to OLP. However, OLRs can be differentiated from OLP lesions. OLR lesions are usually in close proximity to amalgam restorations, and they are usually localized asymmetrically [28]. However, OLP lesions are more widespread and bilateral, with symmetrical occurrence attracting attention. A detailed medical history and clinical and histopathological examinations are important in diagnosing an OLR. The differential diagnosis of OLRs from other oral diseases, such as bullous diseases, leukoplakia, lupus erythematosus, etc., can be performed by histopathological examination. The first step in recognition of allergy induced diseases is a detailed history of the present complaint and the clinical course. Hypersensitivity reactions which are cell mediated such as contact dermatitis are demonstrated by using patch testing [29]. The method includes the epicutaneous application of a specific allergen at a defined concentration and in a defined vehicle which will induce a cutaneous inflammatory reaction in a sensitised person, but will cause no reaction in a non-sensitised person. Fregrert [30] and many others $[16,31,32]$ described a standard series of dental materials applied to the skin to carry out the epicutaneous test. Hensten-Apaettersen and Holland composed a standard series of allergens for use in epicutaneous tests to elucidate possible contact allergy to amalgam [30]. Dental series epicutaneous test batteries of patch test (Trolab ${ }^{\circledR}$ allergens, Trolab Biodiagnostics Ltd, Worcestershire, UK) are also commonly used [33]. Namikoshi et al., [34] performed an epicutaneous patch test in 95 participants and found eight of the 17 allergic responders (in which $10.5 \%$ were positively tested with mercury) had a history of dermatitis from metal contact. Also, many anti-amalgamists use a patch test with a dilute solution of corrosive mercury salts that cause the skin to redden and possibly swell. The reaction is misinterpreted as a sign of mercury allergy or toxicity $[35,36]$ and furthermore the National Council Against Health Fraud recommended in 2002 that there is no logical reason to worry about the safety of amalgam fillings.

In the present case the restorations were removed under rubber dam and high suction and were replaced with an intermediate restorative material. The lesions healed up after removal of the stimuli. This clearly differentiates the lesion from the OLP, which is usually without an etiology. In patients of OLR, a positive patch test to components of amalgam may help to confirm the diagnosis. Final confirmation, however, depends upon resolution of the lesion after removal of the offending amalgam restoration. When the amalgam restoration has to be removed, it should always be done using rubber dam, abundant irrigation, and high aspiration volume, to diminish the exposition of the material [37-39].

\section{Conclusion}

It is recommended that patch tests should be performed in patients with OLR if the lesions are in close contact with amalgam fillings. Replacement of such restorations is recommended if there is a positive patch test reaction to mercury or components 
of amalgam and if there are no signs of concomitant generalized lichen planus.

\section{Competing interests}

The authors declare that they have no competing interests.

\section{Authors' contributions}

All authors contributed equally to the manuscript.

\section{Publication history}

Received: 19 September 2014 Revised: 22 October 2014

Accepted: 28 October 2014 Published: 06 November 2014

\section{References}

1. Athavale PN, Shum KW, Yeoman CM and Gawkrodger DJ. Oral lichenoid lesions and contact allergy to dental mercury and gold. Contact Dermatitis. 2003; 49:264-5. | Article | PubMed

2. Laeijendecker R, Dekker SK, Burger PM, Mulder PG, Van Joost T and Neumann $\mathrm{MH}$. Oral lichen planus and allergy to dental amalgam restorations. Arch Dermatol. 2004; 140:1434-8. | Article | PubMed

3. Udoye $C$ and Aguwa $E$. Amalgam safety and dentists' attitude: a survey among a Subpopulation of Nigerian dentists. Oper Dent. 2008; 33:46771. | Article | PubMed

4. Malamed SF and Quinn CL. Electronic dental anesthesia in a patient with suspected allergy to local anesthetics: report of case. J Am Dent Assoc. 1988; 116:53-5. | Article | PubMed

5. Norris LH and Papageorge MB. The poisoned patient. Toxicologic emergencies. Dent Clin North Am. 1995; 39:595-619. | PubMed

6. Kaaber S. Allergy to dental materials with special reference to the use of amalgam and polymethylmethacrylate. Int Dent J. 1990; 40:359-65. I PubMed

7. Shah M, Lewis FM and Gawkrodger DJ. Delayed and immediate orofacial reactions following contact with rubber gloves during dental treatment. Br Dent J. 1996; 181:137-9. | PubMed

8. McGivern B, Pemberton M, Theaker ED, Buchanan JA and Thornhill MH. Delayed and immediate hypersensitivity reactions associated with the use of amalgam. Br Dent J. 2000; 188:73-6. | PubMed

9. Duxbury AJ, Ead RD, McMurrough $S$ and Watts DC. Allergy to mercury in dental amalgam. Br Dent J. 1982; 152:47-8. I PubMed

10. Eley BM. The future of dental amalgam: a review of the literature. Part 6: Possible harmful effects of mercury from dental amalgam. Br Dent J. 1997; 182:455-9. | PubMed

11. Enestrom $S$ and Hultman P. Does amalgam affect the immune system? A controversial issue. Int Arch Allergy Immunol. 1995; 106:180-203. I Article | PubMed

12. Dunsche A, Kastel I, Terheyden H, Springer IN, Christophers E and Brasch J. Oral lichenoid reactions associated with amalgam: improvement after amalgam removal. Br J Dermatol. 2003; 148:70-6. | Article | PubMed

13. Thorn JJ, Holmstrup P, Rindum J and Pindborg JJ. Course of various clinical forms of oral lichen planus. A prospective follow-up study of 611 patients. J Oral Pathol. 1988; 17:213-8. | PubMed

14. Eisen D, Carrozzo M, Bagan Sebastian JV and Thongprasom K. Number V Oral lichen planus: clinical features and management. Oral Dis. 2005; 11:338-49. | Article | PubMed

15. Scully C, Beyli M, Ferreiro MC, Ficarra G, Gill Y, Griffiths M, Holmstrup P, Mutlu S, Porter S and Wray D. Update on oral lichen planus: etiopathogenesis and management. Crit Rev Oral Biol Med. 1998; 9:86122. | PubMed

16. Lundstrom IM. Allergy and corrosion of dental materials in patients with oral lichen planus. Int J Oral Surg. 1984; 13:16-24. I PubMed

17. Yiannias JA, el-Azhary RA, Hand JH, Pakzad SY and Rogers RS, 3rd. Relevant contact sensitivities in patients with the diagnosis of oral lichen planus. J Am Acad Dermatol. 2000; 42:177-82. | Article | PubMed

18. Laine J, Kalimo K and Happonen RP. Contact allergy to dental restorative materials in patients with oral lichenoid lesions. Contact Dermatitis. 1997; 36:141-6. | Article | PubMed

19. Ostman PO, Anneroth $G$ and Skoglund A. Oral lichen planus lesions in contact with amalgam fillings: a clinical, histologic, and immunohistochemical study. Scand J Dent Res. 1994; 102:172-9. I PubMed

20. Pecegueiro M, Sachse MF, Amaro J, Farinha P and Fonseca I. Oral lichen planus versus oral lichenoid eruption as a manifestation of contact allergy. Contact Dermatitis. 1999; 40:333-4. | Article | PubMed

21. Bratel J, Hakeberg $M$ and Jontell $M$. Effect of replacement of dental amalgam on oral lichenoid reactions. J Dent. 1996; 24:41-5. | Article | PubMed

22. Jolly M, Moule AJ, Bryant RW and Freeman S. Amalgam-related chronic ulceration of oral mucosa. Br Dent J. 1986; 160:434-7. I PubMed

23. Laine J, Kalimo K, Forssell $H$ and Happonen RP. Resolution of oral lichenoid lesions after replacement of amalgam restorations in patients allergic to mercury compounds. Br J Dermatol. 1992; 126:10-5. | Article I PubMed

24. McGivern B, Pemberton M, Theaker ED, Buchanan JA and Thornhill MH. Delayed and immediate hypersensitivity reactions associated with the use of amalgam. Br Dent J. 2000; 188:73-6. | PubMed

25. De Rossi SS and Greenberg MS. Intraoral contact allergy: a literature review and case reports. J Am Dent Assoc. 1998; 129:1435-41. | Article I PubMed

26. Dunsche A, Frank MP, Luttges J, Acil Y, Brasch J, Christophers E and Springer IN. Lichenoid reactions of murine mucosa associated with amalgam. Br J Dermatol. 2003; 148:741-8. | Article | PubMed

27. Aggarwal V, Jain A and Kabi D. Oral lichenoid reaction associated with tin component of amalgam restorations: a case report. Am J Dermatopathol. 2010; 32:46-8. | Article | PubMed

28. Lamey PJ, McCartan BE, MacDonald DG and MacKie RM. Basal cell cytoplasmic autoantibodies in oral lichenoid reactions. Oral Surg Oral Med Oral Pathol Oral Radiol Endod. 1995; 79:44-9. | Article | PubMed

29. Adams S. Allergies in the workplace. Curr Opin related to amalgam. $A d v$ Dent Res, Allergy Clin Immunol. 2006; 19:82-86.

30. Holmstrup P. Oral mucosa and skin reactions related to amalgam. $A d v$ Dent Res. 1992; 6:120-4. | Article | PubMed

31. Djerassi $E$ and Berova $N$. The possibilities of allergic reactions from silver amalgam restorations. Int Dent J. 1969; 19:481-8. | PubMed

32. White IR and Smith BG. Dental amalgam dermatitis. Br Dent J. 1984; 156:259-60. | PubMed

33. Ismail SB, Kumar SK and Zain RB. Oral lichen planus and lichenoid reactions: etiopathogenesis, diagnosis, management and malignant transformation. J Oral Sci. 2007; 49:89-106. | Article | PubMed

34. Namikoshi T, Yoshimatsu T, Suga K, Fujii H and Yasuda K. The prevalence of sensitivity to constituents of dental alloys. J Oral Rehabil. 1990; 17:377-81. | Article | PubMed

35. National Council Against Health Fraud. Position Paper on Amalgam Fillings. 2002.

36. Fisher AA. The misuse of the patch test to determine "hypersensitivity" to mercury amalgam dental fillings. Cutis. $1985 ; 35: 110,112,117$. । PubMed

37. Atesagaoglu A, Omurlu H, Ozcagli E, Sardas S and Ertas N. Mercury 
Uzun et al. Oral Biology and Dentistry 2014,

http://www.hoajonline.com/journals/pdf/2053-5775-2-12.pdf

exposure in dental practice. Oper Dent. 2006; 31:666-9. | Article | PubMed

38. Gordan VV, Riley JL, 3rd, Blaser PK and Mjor IA. 2-year clinical evaluation of alternative treatments to replacement of defective amalgam restorations. Oper Dent. 2006; 31:418-25. | Article | PubMed

39. Szep S, Baum C, Alamouti C, Schmidt D, Gerhardt T and Heidemann D. Removal of amalgam, glass-ionomer cement and compomer restorations: changes in cavity dimensions and duration of the procedure. Oper Dent. 2002; 27:613-20. | PubMed

\section{Citation:}

Uzun I, Güler B, Özyürek T and Gündüz K. Oral

lichenoid contact lesion to amalgam restoration: a case report. Oral Biol Dent. 2014; 2:12.

http://dx.doi.org/10.7243/2053-5775-2-12 